\title{
Information Assurance: The Way to Introduce In PG Education in India-A Policy Framework
}

\author{
P. K. Paul ${ }^{1 *}$, P. S. Aithal ${ }^{2}$ \\ ${ }^{1}$ MCIS, Department of CIS, Raiganj University (RGU), West Bengal, India \\ ${ }^{2}$ Vice Chancellor, Srinivas University, Karnataka, India \\ *Corresponding Author: pkpaul.infotech@gmail.com
}

Available online at: www.isroset.org

Received: 28/Jul/2019, Accepted: 20/Aug/2019, Online: 31/Aug/2019

\begin{abstract}
Information is the core of today's development. Each and every type of organizations and institutions and even individuals today depend on Information. Due to the huge amount of information generation, its management, and security become an important issue and as a result organizations are involving different strategies and techniques towards secure information and computing practice. The traditional documents also emerged hugely in recent past in an organization of its different department and divisions. Initially managing and securing information considered by the discipline of Computing, Information Science, and Information Technologies. But the gradual improved size of data and information led to the development of another subject called Computer Security. Information Technology Security developed thereafter, and that combines few fields viz. Network Security, Web Security, Database Security, etc. The manual information and documents are also important affairs to be noted and as a result, another subject evolved in academics, called 'Information Security'; which incorporates existing IT Security. Information Assurance is the latest name in this context. This paper is conceptual in nature and kind of policy talks about the potential program on Information Assurance and allied nomenclature.
\end{abstract}

Keywords - Information, Information Security, Higher Education, UGC, India, Information Science, Information Assurance, MSc- Information Assurance

\section{INTRODUCTION}

The field Information Assurance is rising rapidly internationally [1], [2]. We can see the nomenclature in different fields and sectors viz. as educational institutes, educational programs, association or society, ministries, departments, etc. As the field Information Assurance is growing and broadest in nature so that universities are offering the branch as well and in such case, the curricula include technological aspects and courses on security and also manual aspects of security [5], [7]. The field Information Assurance highly believes in following aspects of security-

- Managerial affairs of Security and Privacy

- Legal affairs of Security and Privacy

- Social affairs of Security and Privacy

- Ethical and Psychological affairs of Security and Privacy etc.

It is worthy to note that the latest technologies viz. Cloud Systems, Mobile Systems, Big Data Systems, and their development also led the issues and problems in security and thus these are also emerging area of Information
Assurance [3], [4], [8]. The branch incorporated as the areas of Cyber Security as well. The development of Information Infrastructure is an emerging aspect in Information Science and thus various affairs leading to its security and privacy is an important concern in Information Assurance. There is a worldwide shortage of skilled and theoretical experts in the security field and thus many international universities offering the branch as a program leading to Masters and even Doctoral degrees.

\section{OBJECTIVE AND AGENDA}

As the current paper entitled 'Information Assurance: The way to introduce in PG Education in India-A Policy Framework' is theoretical in nature and also a kind of policy, so it is undertaken for the following purpose-

- To learn about the basics of Information Assurance including its meaning and concept.

- To find out the stakeholders, sub-fields of Information Assurance and allied fields.

- To find out the educational opportunities in the field in international universities and also similar or allied programs in India. 
- To find out the potentialities of Information Assurance as a branch of study in Indian universities as a PG program.

- To learn about the way to introduce Information Assurance and allied nomenclature as PG Degree and Diploma in Indian Universities.

- To find out the challenges, opportunities, and issues concerning Information Assurance PG program initiation in Indian Universities.

Information Assurance: Overview \& Characteristics in the light of its Need as an Educational Program

Worldwide many universities viz. Davenport University, Nova South Eastern University, Sam Houston University in US; King Fahd University of Petroleum \& Minerals in UAE, etc. The reason behind this emerging degree is many if we analyzed the following it may clear-

- Information Assurance is responsible for information availability to different individual in the right place and time.

- Data and information privacy, protection from unauthorized and illegal access is the core of Information Assurance [6], [9].

- As we know the technological security depends on information technology security, and IT security is on Information Security. The whole process can be managed by a healthy Information Assurance practice.

- Information Assurance as deals with the social, legal, political and economic affairs so it may solve the problem in cyber terrorism, cyber war, etc.

- Information Assurance is dedicated to the secure mobile services, ensure network privacy, security and assurance, secure database and so on.

- The design, development, implementation, modernization and securing database and information system is the core of Information Assurance.

- Strategies risk management in information and technological space become easily possible in healthy Information Assurance practice.

- Information assurance is responsible for malicious attack prevention and hacking.

- Fraud management dependable system design and development is the core of IT Security these days and here Information Assurance play a leading role.

- Information transparency and public right and services become easy with healthy Information Assurance practice [8], [12], [13].

- The holistic development of computational and manual information system, in term of security, is possible with Information Assurance.

- Information, cyber and IT related policy designing and development is the emerging of Information Assurance.
Information Assurance and Allied Education

Information Science is a vast field comprises with many fields of study and practice. Within Information Science, Security is an important issue and practice. The security field comprises with Cyber Security, Information Technology Security, Computer Security with Cryptography, few other areas viz. Information Security, Information and Data Privacy etc [8], [10], [11]. Information Assurance as a branch of study and practice is available in many universities and higher educational institutions internationally. And sometimes the nomenclature varies and available as merged domains and fields-

- Information Security and Assurance

- Information Assurance and Computing

- Information Systems and Assurance

- IT Security and Assurance

- Cyber Security and Assurance

- Cyber Security and Information Assurance etc.

\section{INDIA AND UG EDUCATION IN COMPUTING AND INFORMATION FIELD}

India is one of the largest education systems in the world, and having different kind of institutions in its pocket viz. Universities, Institution of National Importance, Colleges, Autonomous Institute, etc [5], [7]. These institutes offer various Computing and IT related programs in different levels, viz. Certificate, Diploma, Advanced Diploma, Post Graduate Diploma, Bachelors, Masters, Doctoral Degrees, etc and some of the popular nomenclature are includes-

- Computer Science

- Computer Applications

- Computer Science and Engineering (CSE)

- Information Technology (IT)

- Information Systems

- Software Engineering etc

And many of these branches available as Engineering Track as well (mainly CSE, IT), apart from Science track; while other subjects available as a Science stream leasing to B.Sc., M.Sc. degree. It is worthy to note that unlike western universities in India the awareness and availability of specialized or field of IT and Computing as a program is rarely noted.

\section{Way to Introduce IA in Indian Academics at PG}

Indian Education Systems is the largest in the world, which include a different kind of Higher Educational Institute (HEIs), viz. Institute of National Importance viz. IITs, NITs, IIMs, etc, Universities viz. Central, State, Private, Deemed, Colleges of various kinds viz. Government, Government Aided, Private, Autonomous, Constituent, Affiliated, General of Discipline Specific, or Subject Specific, Morning, Day, Evening, Weakened, etc. 
The Faculties and Departments related to the Information Technology mentioned above may introduce PG programs as full-fledged manner or as a Major or Specializations in allied fields, viz. in Engineering and Technology stream the following IT related PG degrees may be offered (refer Table: 1$)$.

Table: 1-In Engineering and Technology Stream Information Assurance Full-fledged and Major Degrees Information Assurance

\begin{tabular}{c} 
Engineering \& Technology \\
ME/MTech (Information Assurance) \\
ME/MTech IT (Information Assurance) \\
ME/MTech Software Engineering (Information Assurance \\
\& Secure Software) \\
ME/MTech Computer Science \& Engineering (Information \\
Assurance) \\
\hline
\end{tabular}

The Science field is also popular and commonly available among the degrees popular degrees like M.Sc., MS are important. Based on IT related subjects, the Information Assurance branch may be incorporated. And few possible programs are listed as in Table: 2 .

Table: 2-In Science Stream Possible Information Assurance Full-fledged and Major Degrees in Information Assurance

\begin{tabular}{|c|}
\hline Sciences \\
\hline MSc/MS (Information Assurance) \\
MSc/MS IT (Information Assurance) \\
MSc/MS Software Engineering (Information Assurance \& \\
Secure Software) \\
MSc/MS Computer Science \& Engineering (Information \\
Assurance) \\
\hline
\end{tabular}

It was noted that the Information Technology related subjects are available in different allied form and nomenclature with various degrees. And among these, MCA degree is another popular one and most valuable. Hence MCA degree may be started in Information Assurance and allied nomenclature as depicted in Table: 3 .

Table: 3-In Computer Application Stream Possible Information Assurance Major

Information Assurance in Computer Applications platform

MCA (Information Assurance)

MCA (Information Security and Assurance)

MCA (Information Assurance and Computing)

MCA (Information Systems and Assurance)

MCA (IT Security and Assurance)

MCA (Cyber Security and Assurance)

MCA (Cyber Security and Information Assurance)
However, as the degree, MCA is widely available (in more than 5000 institutes), and common thus apart from the listed (in table: 3) possible programs, Information Assurance may be merged with a specific area or the field and among the possible program few listed are Table: 4.

Table: 4-In Computer Application Stream Possible Information Assurance with sub field Major

Information Assurance and Its Specialization in Computer Applications platform

MCA (Information Assurance with Network Security) MCA (Information Security with Cloud Security) MCA (Information Assurance with Web Security) MCA (Information Assurance with Mobile Security) MCA (Information Assurance with Database Security)

The research based degrees are gaining popularity in International universities and the field Information Assurance is theoretical and interdisciplinary in nature. Thus based on potentialities Information Assurance may be introduced as MSc/MS etc. Some potential programs have been listed in Table: 5 .

Table: 5- Possible Information Assurance degrees in Research track Research Based PG Degrees

MSc by Research (Information Assurance)

MSc (Engg.) by Research (Information Assurance) MS by Research (Information Assurance)

MTech by Research (Information Assurance) ME by Research (Information Assurance)

\section{ISSUES AND CHALLENGES}

- Indian education system is conservative in nature and slowing developing their style of delivery of teaching, learning etc. As an interdisciplinary program, Information Assurance teaching needs interdisciplinary knowledge and skill sets among its faculty member.

- Information Assurance is a vast field and thus the knowledge seeker and providers both should have diverse knowledge in all the components of Information Assurance viz. IT Security areas, etc.

- Different sub fields of IT Security is purely skill based and thus for its real solutions industrial tie ups would be perfect.

- Unwillingness towards changing the nomenclature is another burden in Indian Higher educational institute among its administrators, faculties, etc.

- Government bodies, policy makers needs to hold proper policy to launch the full-fledged degrees or major in Information Assurance and allied fields. 


\section{CONCLUSION}

Cyber Security and its challenge is the need of the hour for managing and securing information. It is a fact that today each and every organization and institute are facing challenges regarding security and there are huge needs for cyber and information security related awareness, skills and technologies. Today, the concept of security is rising and within this, mobile security, cloud computing security and risk management become an important issue. In today's Digital Age every kind of institutions, Government bodies and organizations, and individuals depend on information and for its security proper techniques, tools are threat highly desired. Apart from the computational security, traditional information are also rising and its management also needs of the hour. Due to the importance of the contents and its value, data and information privacy becomes a vital tool. Higher education segment in India is raising a lot and different universities have started various PG Degrees. As per the need of time, the Information Assurance field has emerged as a field of study and available as a program of study in many international universities. In India, there are huge numbers of educational institutes and lots of PG program has been started and thus there is a scope to offer the Information Assurance and allied field as a PG degree or Major program.

\section{REFERENCES}

[1] Bulgurcu, B., Cavusoglu, H., \& Benbasat, I. (2010). Information security policy compliance: an empirical study of rationalitybased beliefs and information security awareness. MIS quarterly, 34(3), 523-548.

[2] Burkell, J., \& Carey, R. (2011). Personal Information and the Public Library: Compliance with Fair Information Practice Principles/Les renseignements personnels dans les bibliothèques publiques: le respect des principes d'équité dans les pratiques de collecte de renseignements. Canadian Journal of Information and Library Science, 35(1), 1-16.

[3] Ezingeard, J. N., McFadzean, E., \& Birchall, D. (2005). A model of information assurance benefits. Information Systems Management, 22(2), 20-29.

[4] Hamill, J. T., Deckro, R. F., \& Kloeber Jr, J. M. (2005). Evaluating information assurance strategies. Decision Support Systems, 39(3), 463-484.

[5] Höne, K., \& Eloff, J. H. P. (2002). Information security policywhat do international information security standards say? Computers \& security, 21(5), 402-409.

[6] Knapp, K. J., Marshall, T. E., Kelly Rainer, R., \& Nelson Ford, F. (2006). Information security: management's effect on culture and policy. Information Management \& Computer Security, 14(1), 24-36.

[7] Paul, P. K., Chatterjee, D., Bhuimali,A., Atarthy, A. (2016). Cyber Crime: An Important facet for promoting Digital Humanities-A Short Review in Saudi Journal of Humanities and Social Science, 1(1), 13-16

[8] Paul, P. K. \& Aithal, P. S. (2018). Cyber Crime: Challenges, Issues, Recommendation and Suggestion in Indian Context,
International Journal of Advanced Trends in Engineering and Technology, 3(1), 59-62.

[9] Paul, P. K., and Aithal, P. S. (2018) Cyber Security to Information Assurance: The Changing World of Cyber Sciences in Proceedings of National Conference on Quality in Higher education challenges \& opportunities (ISBN: 978-93-5311-0826), Srinivas University, 11-18.

[10] Pérez, L. C., Cooper, S., Hawthorne, E. K., Wetzel, S., Brynielsson, J., Gökce, A. G., ... \& Philips, A. (2011, June). Information assurance education in two-and four-year institutions. In Proceedings of the 16th annual conference reports on Innovation and technology in computer science education-working group reports (pp. 39-53).

[11] Proia, A., Simshaw, D., \& Hauser, K. (2015). Consumer cloud robotics and the fair information practice principles: Recognizing the challenges and opportunities ahead. Minn. JL Sci. \& Tech., 16, 145.

[12] Schou, C. D., \& Trimmer, K. J. (2004). Information assurance and security. Journal of Organizational and End User Computing, 16(3), 123-145. 